ARTICLE

\title{
High-throughput production of cheap mineral-based two-dimensional electrocatalysts for high-current-density hydrogen evolution
}

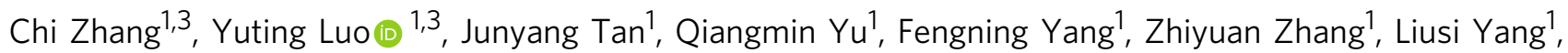
Hui-Ming Cheng (D) ${ }^{1,2} \&$ Bilu Liu (iD ${ }^{1 凶}$

The high-throughput scalable production of cheap, efficient and durable electrocatalysts that work well at high current densities demanded by industry is a great challenge for the largescale implementation of electrochemical technologies. Here we report the production of a two-dimensional molybdenum disulfide-based ink-type electrocatalyst by a scalable exfoliation technique followed by a thermal treatment. The catalyst delivers a high current density of $1000 \mathrm{~mA} \mathrm{~cm}^{-2}$ at an overpotential of $412 \mathrm{mV}$ for the hydrogen evolution. Using the same method, we produce a cheap mineral-based catalyst possessing excellent performance for high-current-density hydrogen evolution. Noteworthy, production rate of this catalyst is one to two orders of magnitude higher than those previously reported, and price of the mineral is five orders of magnitude lower than commercial Pt electrocatalysts. These advantages indicate the huge potentials of this method and of mineral-based cheap and abundant natural resources as catalysts in the electrochemical industry.

\footnotetext{
${ }^{1}$ Shenzhen Geim Graphene Center, Tsinghua-Berkeley Shenzhen Institute \& Tsinghua Shenzhen International Graduate School, Tsinghua University, Shenzhen 518055, P. R. China. ${ }^{2}$ Shenyang National Laboratory for Materials Sciences, Institute of Metal Research, Chinese Academy of Sciences, Shenyang, Liaoning 110016, P. R. China. ${ }^{3}$ These authors contributed equally: Chi Zhang, Yuting Luo. ${ }^{凶}$ email: bilu.liu@sz.tsinghua.edu.cn
} 
T he large-scale production of hydrogen by electrochemical water splitting has been proposed as a promising technology for a sustainable energy source because water is abundant, sustainable, and carbon-free, and the electricity for the hydrogen production can be generated by wind and sunlight $t^{1,2}$. However, the energy consumption in the hydrogen evolution reaction (HER, $2 \mathrm{H}^{+}+2 \mathrm{e}^{-} \rightarrow \mathrm{H}_{2}$ ) is usually high due to its slow reaction kinetics, resulting in the need for efficient and durable electrocatalysts ${ }^{3}$. Platinum $(\mathrm{Pt})$ is the most efficient electrocatalyst for HER, but its abundance is six orders of magnitude lower than aluminum, the most abundant metal ${ }^{4,5}$, making it extremely expensive (ten million US\$ per ton, Supplementary Fig. 1). As a result, the Pt or any other noble metal catalyst accounts for $\sim 8 \%$ of the total stack cost of a proton exchange membrane electrolyzer $^{6}$. Because of this reason, researchers have devoted great effort to exploring Pt-free or low-Pt electrocatalysts, including Pt single atoms ${ }^{7,8}$, Pt-based alloys ${ }^{9,10}$, metal carbides ${ }^{11-13}$, transition metal dichalcogenides (TMDCs) ${ }^{14-20}$, metal phosphides ${ }^{6,21}$, etc. For example, Liu et al. anchored Pt single atoms on carbon nanospheres, and the resulting material showed a comparable HER performance to commercial Pt/C but with less Pt needed ${ }^{7}$. King et al. loaded $\mathrm{CoP}$ nanoparticles on a high-surface-area carbon support, which showed an excellent activity and a longterm stability that were close to commercial $\mathrm{Pt} / \mathrm{C}^{6}$. Although great progress has been made in the low-Pt and Pt-free electrocatalysts, how to achieve the high-throughput production of such catalysts is still a challenge to use water electrolysis. Moreover, the current densities needed by industry are usually higher than 1000 and $500 \mathrm{~mA} \mathrm{~cm}^{-2}$ for proton exchange membrane and alkaline electrolyzers ${ }^{13}$, requiring catalysts with good electrochemical, thermal, and mechanical stabilities, as well as abundant numbers of active sites ${ }^{6,13,22}$. These challenges have motivated the need for the high throughput production of efficient, durable, and cheap electrocatalysts for a high-current-density HER.

Molybdenum disulfide $\left(\mathrm{MoS}_{2}\right)$ is promising for HER because of its high catalytic activity, good stability, and low price. Hinnemann et al. forecast that $\mathrm{MoS}_{2}$ edges would be active for HER with a free adsorption energy of hydrogen close to zero ${ }^{23}$, which was then experimentally verified by Jaramillo et al. using twodimensional (2D) $\mathrm{MoS}_{2}{ }^{15}$ because the $2 \mathrm{D}$ form had more exposed edges than the bulk material ${ }^{16,24,25}$. Our group has recently demonstrated that by combining surface chemistry and morphology engineering, $\mathrm{MoS}_{2}$ showed a good HER performance at current density of $1000 \mathrm{~mA} \mathrm{~cm}^{-2} 13 . \mathrm{MoS}_{2}$ also has a good atmospheric thermal stability (up to $300^{\circ} \mathrm{C}$ ) 26 , a good electrochemical stability under reducing potentials ${ }^{26}$, and is mechanically roubust ${ }^{27,28}$, making it a promising catalyst for high-current density HER. The global proven reserve of Mo is about 500 times that of $\mathrm{Pt}$ and its price is three orders of magnitude lower (Supplementary Fig. 1), making the cheap production of $\mathrm{MoS}_{2}$ based catalysts possible. $\mathrm{MoS}_{2}$ naturally exists as the molybdenite mineral, with a global availability of $17,000,000$ ton $^{4}$. If one can use such a low-cost and abundant mineral to produce suitable catalysts, the overall cost of HER electrocatalysts would be significantly reduced. Despite its good performance and stability, most of the methods to produce $\mathrm{MoS}_{2}$-based catalysts are energy intensive and/or difficult to scale-up due to the use of conditions such as high vacuum ${ }^{15}$, poisonous reactant ${ }^{24,25}$, high pressure $^{13,26}$, or the poor high-current-density HER performance. Therefore, the production of efficient, cheap, and durable $\mathrm{MoS}_{2}$ based catalysts by a high-throughput and scalable way is desired to make a real impact in HER electrochemical technology.

Here, we report a high-throughput scalable method for production of cheap yet high-performance $\mathrm{MoS}_{2}$-based HER catalysts that work well at high current densities up to $1000 \mathrm{~mA} \mathrm{~cm}^{-2}$. We first obtain $2 \mathrm{D} \mathrm{MoS}_{2}$ flakes by a scalable top-down exfoliation method, followed by a simple thermal treatment to prepare the catalyst, with both processes having the possibility of being scaled up for high-throughput production. The catalysts are $2 \mathrm{D} \mathrm{MoS}_{2}$ modified by $\mathrm{Mo}_{2} \mathrm{C}$ nanoparticles on their edges and surfaces, and have a good HER performance with a high current density of $1000 \mathrm{~mA} \mathrm{~cm}^{-2}$ at $412 \mathrm{mV}$, a small Tafel slope of $60 \mathrm{mV} \mathrm{dec}{ }^{-1}$, and good stability for $24 \mathrm{~h}$. We also demonstrate the feasibility of the high-throughput production method by using a cheap molybdenite concentrate from a naturally existing earth-abundant mineral and find that the mineral catalysts also show good HER performance at high current densities. The production rate of the electrocatalyst is as high as $1.3 \mathrm{~g} \mathrm{~h}^{-1}$, one to two orders of magnitude higher than previous results (Supplementary Table 1), and the catalyst price is $\sim 10$ US $\$ \mathrm{~m}^{-2}$, around 30 times lower than than a commercial $\mathrm{Pt} / \mathrm{C}$ electrocatalyst.

\section{Results}

Preparation of $\mathrm{MoS}_{2}$-based ink-type electrocatalysts. A schematic of the process is shown in Fig. 1a. The $\mathrm{MoS}_{2}$-based catalyst

a
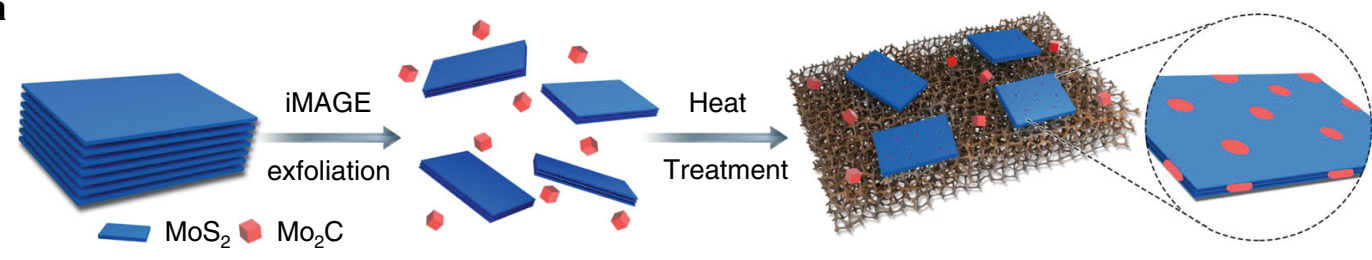

b

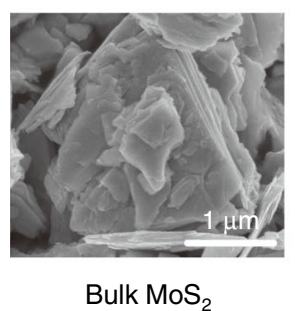

C

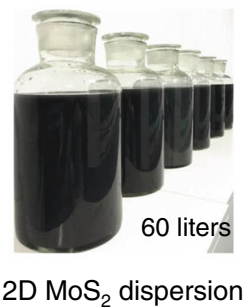

d

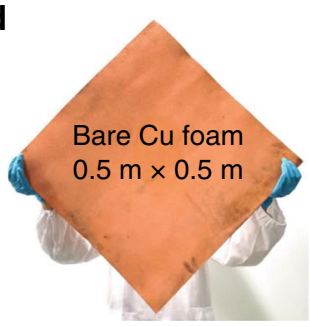

e

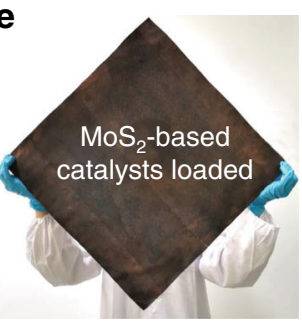

Fig. 1 High-throughput production of molybdenum disulfide $\left.\mathbf{~ M o S}_{\mathbf{2}}\right)$-based ink-type electrocatalysts. a Schematic of the fabrication method of $\mathrm{MoS}_{2}$ based catalysts. b Scanning electron microscopy image of the pristine $\mathrm{MoS}_{2}$ powder, and photos of (c) two-dimensional (2D) MoS 2 aqueous dispersion with a volume of 60 liters, (d) bare copper $(\mathrm{Cu})$ foam and $(\mathbf{e}) \mathrm{MoS}_{2}$-based catalyst loaded on $\mathrm{Cu}$ foam. 
a

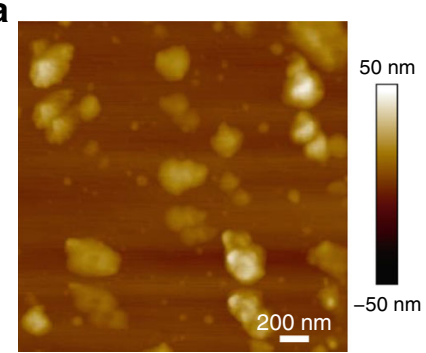

e

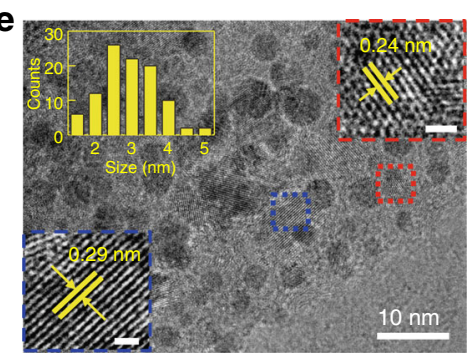

b

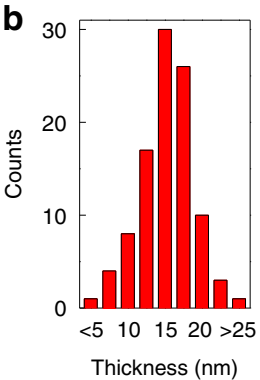

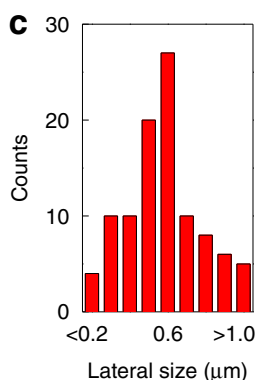

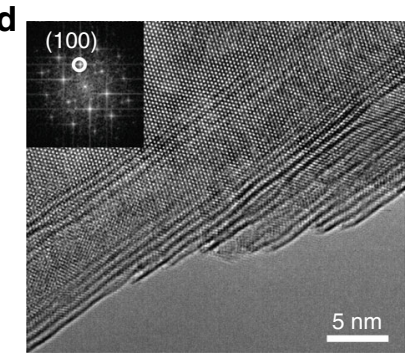

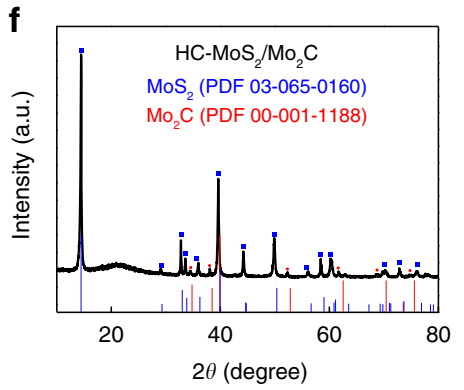

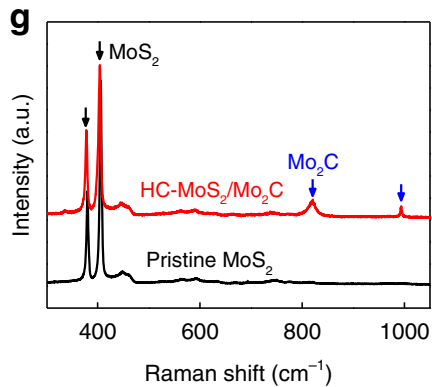

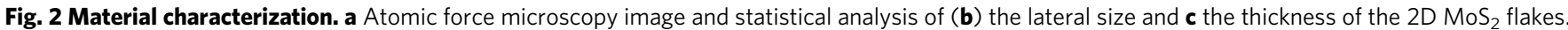
d High resolution transmission electron microscopy (HRTEM) image of the 2D MoS 2 . Inset is the corresponding fast Fourier transform (FFT) pattern. e HRTEM image of the $\mathrm{HC}-\mathrm{MoS}_{2} / \mathrm{Mo}_{2} \mathrm{C}$. The insets are a histogram of the lateral size of the $\mathrm{Mo}_{2} \mathrm{C}$ nanocrystals, and two high magnification HRTEM images of a MoS${ }_{2}$ flake (the blue dotted box) and a $\mathrm{Mo}_{2} \mathrm{C}$ nanocrystal (the red dotted box). The scale bars in the insets are $1 \mathrm{~nm}$. $\mathbf{f} X$-ray diffraction pattern and (g) Raman spectra of the 2D MoS 2 and the $\mathrm{HC}-\mathrm{MoS}_{2} / \mathrm{Mo}_{2} \mathrm{C}$.

was synthesized by a two-step method, i.e., exfoliation of bulk $\mathrm{MoS}_{2}$ into 2D flakes followed by thermal treatment (see details in the "Methods" section). In brief, $2 \mathrm{D} \mathrm{MoS}_{2}$ was first prepared by exfoliating bulk $\mathrm{MoS}_{2}$ (Supplementary Fig. 2) by an interMediateAssisted Grinding Exfoliation (iMAGE) technique that was able to obtain $2 \mathrm{D}$ materials at the tonne $\mathrm{scale}^{28}$. Here we used a modified iMAGE technique that used $\mathrm{Mo}_{2} \mathrm{C}$ as the force intermediary to facilitate the exfoliation of $\mathrm{MoS}_{2}$ because it has a low electrical resistivity $(57 \mu \Omega \mathrm{cm})$ and a high hardness (Moh's hardness is 7 $)^{29}$. The $2 \mathrm{D} \mathrm{MoS}$ flakes were then dispersed in water to obtain a catalyst dispersion, which is ink-type and is suitable to be integrated with robust industrial used techniques to produce large-area electrodes such as dip-coating, drop-casting, roll-toroll printing, screen printing, and spray coating. Here, the exfoliated $\mathrm{MoS}_{2}$ flakes together with $\mathrm{Mo}_{2} \mathrm{C}$ were loaded by dip coating onto supports with high surface areas (e.g., carbon cloth, $\mathrm{Ti}$ substrate, $\mathrm{Cu}$ foam) for the $\mathrm{CH}_{4} / \mathrm{H}_{2}$ thermal treatment, after which 2D MoS 2 became a suitable catalyst for the subsequent $\mathrm{HER}$ test (denoted as $\mathrm{HC}-\mathrm{MoS}_{2} / \mathrm{Mo}_{2} \mathrm{C}$, where "HC" means $\mathrm{CH}_{4} / \mathrm{H}_{2}$ thermal treatment). To optimize the HER performance of the catalyst, the thermal treatment was divided into two parts, i.e., first the desulfurization using $\mathrm{H}_{2}$ as the reacting gas to form $\mathrm{S}$ vacancies on $2 \mathrm{D} \mathrm{MoS}_{2}$, and second the carburization using $\mathrm{CH}_{4} / \mathrm{H}_{2}$ as the reacting gases to produce $\mathrm{Mo}_{2} \mathrm{C}$ nanoparticles on 2D $\mathrm{MoS}_{2}{ }^{13}$. In the first stage, $S$ vacancies were formed by the reaction of $\mathrm{H}_{2}$ with $\mathrm{S}$ in the $\mathrm{MoS}_{2}$, removing $\mathrm{S}$ atoms to form $\mathrm{H}_{2} \mathrm{~S}$, while in the second stage $\mathrm{CH}_{4}$ reacted with Mo atoms near the vacancies to form $\mathrm{Mo}_{2} \mathrm{C}$ by dehydrogenation ${ }^{30}$. Both processes involved mild conditions and could be scaled-up for the highthroughput production of $\mathrm{MoS}_{2}$-based catalysts. Examples of several $\mathrm{MoS}_{2}$-based catalysts on different supports prepared by this method are shown in Fig. 1b-d and S3.

Structure characterization of the catalysts. We characterized the structures of the $\mathrm{MoS}_{2}$ materials after the first exfoliation step and the second thermal treatment step. To expose more $\mathrm{MoS}_{2}$ edges, we choose a bulk $\mathrm{MoS}_{2}$ material with a relatively small lateral size $(\sim 1 \mu \mathrm{m})$. Atomic force microscopy (AFM) showed that after the first exfoliation step, the bulk $\mathrm{MoS}_{2}$ was exfoliated into 2D MoS flakes (Fig. 2a) with an average thickness of $15 \mathrm{~nm}$ (Fig. 2b) and an average lateral size of $0.6 \mu \mathrm{m}$ (Fig. 2c), consistent with the results of dynamic light scattering (DLS, Supplementary Fig. 4), transmission electron microscopy (TEM, Supplementary Fig. 5), and scanning electron microscopy (SEM, Supplementary Fig. 5). The uniformity of the 2D $\mathrm{MoS}_{2}$ was demonstrated by combined AFM, SEM, and TEM characterization. In addition, results from high resolution transmission electron microscopy (HRTEM) and the corresponding fast Fourier transformation (FFT) showed the high quality of the $2 \mathrm{D} \mathrm{MoS}$ flakes without noticeable defects in their basal planes and edges (Fig. 2d and Supplementary Fig. 6). The above results show that in the first step the bulk $\mathrm{MoS}_{2}$ was exfoliated into 2D $\mathrm{MoS}_{2}$ flakes with good uniformity and high quality.

After the second thermal treatment step, we confirmed the formation of $\mathrm{Mo}_{2} \mathrm{C}$ nanocrystals on the $2 \mathrm{D} \mathrm{MoS}_{2}$ by HRTEM, Xray diffraction (XRD), and Raman spectroscopy. The HRTEM images show that in the final optimized $\mathrm{HC}-\mathrm{MoS}_{2} / \mathrm{Mo}_{2} \mathrm{C}$ catalyst, $\alpha-\mathrm{Mo}_{2} \mathrm{C}$ nanocrystals were formed both on the basal planes and edges of $2 \mathrm{D} \mathrm{MoS}$ flakes (Fig. 2e and Supplementary Fig. 7). The growth of $\mathrm{Mo}_{2} \mathrm{C}$ nanocrystals in these positions is easy to understand because $\mathrm{S}$ vacancies and unsaturated Mo existed there, which facilitated their formation. Higher magnification HRTEM images show typical lattice spacings of $0.29 \mathrm{~nm}$ and $0.24 \mathrm{~nm}$, which, respectively, correspond to the (100) planes of $\mathrm{MoS}_{2}$ (blue dotted box in Fig. 2e) and the (002) planes of $\alpha-\mathrm{Mo}_{2} \mathrm{C}$ (red dotted box in Fig. 2e). Statistical analysis shows that the $\mathrm{Mo}_{2} \mathrm{C}$ nanocrystals (inset of Fig. 2e) have an average diameter of $2.8 \mathrm{~nm}$ and a narrow size distribution, and are evenly distributed over the 2D $\mathrm{MoS}_{2}$ basal planes. Regarding the XRD patterns (Fig. 2f and Supplementary Fig. 8), the $\mathrm{MoS}_{2}$ (002) peak is quite sharp, indicating the high crystallinity of the $\mathrm{MoS}_{2}$. The peaks at 
$34.5^{\circ}$ and $38.1^{\circ}$ correspond to the (100) and (002) planes of $\mathrm{Mo}_{2} \mathrm{C}$. Moreover, Raman spectroscopy was also used to identify the structures of the $\mathrm{HC}-\mathrm{MoS}_{2} / \mathrm{Mo}_{2} \mathrm{C}$ (Fig. $2 \mathrm{~g}$ ). In addition to the $\mathrm{MoS}_{2}$ peaks, those at 812 and $987 \mathrm{~cm}^{-1}$ indicate the formation of $\mathrm{Mo}_{2} \mathrm{C}^{31}$. Note that a lateral heterostructure made of $\mathrm{MoS}_{2} / \alpha$ $\mathrm{Mo}_{2} \mathrm{C}$ has been constructed. Taking these results together, we can say that the $\mathrm{HC}-\mathrm{MoS}_{2} / \mathrm{Mo}_{2} \mathrm{C}$ is composed of $2 \mathrm{D} \mathrm{MoS}$ flakes with a large number of $\mathrm{Mo}_{2} \mathrm{C}$ nanocrystals on their basal planes and edges, and good uniformity of the catalyst is achieved by this method.

HER performance at high current densities. To evaluate the electrochemical performance of the catalysts, we used a standard three-electrode electrolyzer. All the electrochemical characterization was conducted using the same cell and the same test parameters (Supplementary Fig. 9). The distance between the working and reference electrodes was optimized to measure the HER performance at high current densities and the catalysts were tailored to ensure identical electrode surface areas (Supplementary Fig. 10). The HER performance of catalysts was compared by the overpotential $(\eta)$ as given in the following equation:

$$
\eta=E_{\text {appl }}-E_{\text {eq }}-\mathrm{i} R_{\mathrm{s}},
$$

where $E_{\text {appl }}$ and $E_{\text {eq }}$ are the practical applied and theoretical electrochemical equilibrium potentials ( $0 \mathrm{~V}$ vs RHE for HER), and $\mathrm{i} R_{\mathrm{s}}$ is the solution resistance drop. Several key parameters such as the nature of the supports, the loading amount of $2 \mathrm{D}$ $\mathrm{MoS}_{2}$ flakes, as well as the temperature and time for the desulfurization and carburization processes have been systematically studied and optimized (Supplementary Figs. 3, 11, and 12). Based on the best samples obtained, we characterized and compared the HER performance of the $\mathrm{HC}-\mathrm{MoS}_{2} / \mathrm{Mo}_{2} \mathrm{C}$ with other samples, a series of Pt-based catalysts, bare $\mathrm{Cu}$ foam, and $2 \mathrm{D} \mathrm{MoS}_{2}$ without the thermal treatment. Polarization curves of these samples in a $\mathrm{H}_{2} \mathrm{SO}_{4}(0.5 \mathrm{M})$ solutions are shown in Fig. 3a, Supplementary Fig. 13 and Movie 1. The dissolution of $\mathrm{Cu}$ in sulfuric acid and the effect of $\mathrm{Cu}$ support on current densities in HER is negligible in our experiments (Supplementary Fig. 14). Compared to the best $\mathrm{Pt}$ sample with morphology engineering, i.e., $\mathrm{Pt} / \mathrm{C}$ loaded on high-surface-area $\mathrm{Cu}$ foam with a loading mass of $2 \mathrm{mg} \mathrm{cm}^{-2}$, the $\mathrm{HC}-\mathrm{MoS}_{2} / \mathrm{Mo}_{2} \mathrm{C}$ needed a larger overpotential to obtain an identical current density $(j)$ at small current densities, suggesting that it has a lower intrinsic activity than Pt (Supplementary Fig. 15 and 16). Tafel plots were used to study the ratedetermining step of the catalysts (Fig. $3 \mathrm{~b}$ ) and the results show that the $\mathrm{HC}-\mathrm{MoS}_{2} / \mathrm{Mo}_{2} \mathrm{C}$ has a small slope of $60 \mathrm{mV} \mathrm{dec}{ }^{-1}$, indicating that the recombination of hydrogen is its rate-limiting step $^{32}$. As current density increased to over $400 \mathrm{~mA} \mathrm{~cm}^{-2}$, the $\mathrm{HC}-\mathrm{Mo}_{2} \mathrm{~S} / \mathrm{Mo}_{2} \mathrm{C}$ required comparable overpotentials to obtain the same current density to the Pt-based catalysts (Supplementary Fig. 17 and Table 2). For instance, the $\mathrm{HC}-\mathrm{MoS}_{2} / \mathrm{Mo}_{2} \mathrm{C}$ needed $412 \mathrm{mV} @ 1000 \mathrm{~mA} \mathrm{~cm}^{-2}$, while the respective values for $0.5 \mathrm{mg}$ $\mathrm{cm}^{-2} \mathrm{Pt} / \mathrm{C}$ and $2 \mathrm{mg} \mathrm{cm}^{-2} \mathrm{Pt} / \mathrm{C}$ were $511 \mathrm{mV}$ and $400 \mathrm{mV}$. These results show the superior HER performance of the $\mathrm{HC}-\mathrm{MoS}_{2} /$ $\mathrm{Mo}_{2} \mathrm{C}$ at high current densities. Moreover, the $\mathrm{HC}-\mathrm{MoS}_{2} / \mathrm{Mo}_{2} \mathrm{C}$ gives a nearly $100 \%$ Faradaic efficiency during HER (Supplementary Fig. 18). Neither the 2D $\mathrm{MoS}_{2}$ without the thermal treatment nor the bare $\mathrm{Cu}$ foam showed such a performance as the current density increased. Note that for the sample without the thermal treatment, the $2 \mathrm{D} \mathrm{MoS}_{2}$ flakes fell from the support as current density increased and made the catalytic performance even poorer, caused by the forces of $\mathrm{H}_{2}$ bubbles (Supplementary Fig. 19 and Movie 2). In sharp contrast, the $\mathrm{HC}-\mathrm{MoS}_{2} / \mathrm{Mo}_{2} \mathrm{C}$ was tightly attached to the $\mathrm{Cu}$ foam support and showed good mechanical stability at high current densities (Supplementary
Movie 1). An SEM image of the $\mathrm{HC}-\mathrm{MoS}_{2} / \mathrm{Mo}_{2} \mathrm{C}$ showed a soldering-like phenomenon between the $\mathrm{HC}-\mathrm{MoS}_{2} / \mathrm{Mo}_{2} \mathrm{C}$ and the $\mathrm{Cu}$ support, indicating that thermal treatment may be a good way to improve the mechanical robustness of electrocatalysts. The soldering effect could not only provide good electrical contact to improve catalytic performance but also enhance the robustness of the electrode, which is not a necessary result achieved during usual annealing or heat treatment. In addition, the $\mathrm{HC}-\mathrm{MoS}_{2} /$ $\mathrm{Mo}_{2} \mathrm{C}$ catalyst showed a pH-universal HER activity and worked well in a $1.0 \mathrm{M} \mathrm{KOH}$ solution (Fig. 3a, Supplementary Figs. 20 and 21).

For practical applications, the high-current-density performance of catalysts is of vital importance. To evaluate the HER performance of the $\mathrm{HC}-\mathrm{MoS}_{2} / \mathrm{Mo}_{2} \mathrm{C}$ in such conditions, we analyzed the relationships between current densities and $\Delta \eta / \Delta \log |j|$, which can be viewed as a generalized slope and can be used to evaluate the performance of catalysts at high current densities ${ }^{13}$. The $\mathrm{Pt} / \mathrm{C}$ showed an increasing $\Delta \eta / \Delta \log |j|$ ratio as current density increased, whereas the $\mathrm{HC}-\mathrm{MoS}_{2} / \mathrm{Mo}_{2} \mathrm{C}$ maintained a small ratio at different current densities, indicating that it had an excellent HER performance at high current densities (Fig. 3c). To understand the different performances of the $\mathrm{HC}-\mathrm{MoS}_{2} / \mathrm{Mo}_{2} \mathrm{C}$ and Pt catalysts, their mass transfer abilities were studied. The diameters of the $\mathrm{H}_{2}$ bubbles remained small on $\mathrm{HC}-\mathrm{MoS}_{2} / \mathrm{Mo}_{2} \mathrm{C}$ (Fig. 3d), while they became larger on $\mathrm{Pt}$ catalyst as current density increased ${ }^{13}$. Moreover, in $\mathrm{HC}-\mathrm{MoS}_{2} / \mathrm{Mo}_{2} \mathrm{C}$ we did not observe the fluctuation phenomenon at high current densities that is seen for $\mathrm{Pt}$ foil and $\mathrm{Pt}$ mesh (Supplementary Fig. 17), which might be related to the fast removal of $\mathrm{H}_{2}$ bubbles from the surface of $\mathrm{HC}-\mathrm{MoS}_{2} / \mathrm{Mo}_{2} \mathrm{C}$. We confirmed this point by studying the time-dependent (30 frames per second) transport of $\mathrm{H}_{2}$ bubbles on $\mathrm{HC}-\mathrm{MoS}_{2} / \mathrm{Mo}_{2} \mathrm{C}$, which showed the departure diameters of bubbles on its surface remained small (Fig. 3e). These results indicate the good mass transfer ability of $\mathrm{HC}-\mathrm{MoS}_{2} / \mathrm{Mo}_{2} \mathrm{C}$ at high current densities. Besides mass transfer, we measured the electrochemically active surface areas (ECSA) of these catalysts, which showed that the value for $\mathrm{HC}-\mathrm{MoS}_{2} / \mathrm{Mo}_{2} \mathrm{C}$ was higher than for the other samples and was comparable to $2 \mathrm{mg} \mathrm{cm}^{-2} \mathrm{Pt} / \mathrm{C}$ (Supplementary Fig. 16). Electrochemical impedance spectroscopy (EIS) showed that $\mathrm{HC}-\mathrm{MoS}_{2} / \mathrm{Mo}_{2} \mathrm{C}$ had a small charge transfer resistance (Supplementary Fig. 22). Compared with Pt-based catalysts we tested and previously reported, the $\mathrm{HC}-\mathrm{MoS}_{2} /$ $\mathrm{Mo}_{2} \mathrm{C}$ showed one of the best achievable HER performance at $1000 \mathrm{~mA} \mathrm{~cm}^{-2}$ (Fig. 3f, Supplementary Table 2 and 3). In addition, stability tests showed that $\mathrm{HC}-\mathrm{MoS}_{2} / \mathrm{Mo}_{2} \mathrm{C}$ retained its HER performance over $24 \mathrm{~h}$ at $200 \mathrm{~mA} \mathrm{~cm}^{-2}$ and also at $\sim 500 \mathrm{~mA} \mathrm{~cm}^{-2}$ (Fig. 3g), which was confirmed by SEM images (Supplementary Fig. 19). All these results show that $\mathrm{HC}-\mathrm{MoS}_{2} / \mathrm{Mo}_{2} \mathrm{C}$ has good achievable HER performance, demonstrated by a low overpotential, a small Tafel slope, and a good stability at high current density.

Production of cheap $\mathrm{MoS}_{2}$ mineral catalysts for HER. To realize the large-scale use of electrolyzers, it is important to reduce the cost of all system components, and replacing expensive precious metals with cheap and durable catalysts is a critical step. The high-throughput production of such catalysts can pave the way for their cost reduction as well allowing their use on a large scale. To demonstrate the feasibility of high-throughput production method, we used molybdenite concentrate as the precursor, which is mainly composed of bulk $\mathrm{MoS}_{2}$ in form of molybdenite mineral dug directly from an open-pit mine (Fig. 4a). A molybdenite concentrate is generated by a preliminary floatation treatment that can be used to produce industrial-grade $\mathrm{MoS}_{2}$ as well as high-purity $\mathrm{MoS}_{2}$. Detailed characterization indicated that the molybdenite concentrate mainly composed of crystalline $\mathrm{MoS}_{2}$, as well as molybdenum oxides $\left(\mathrm{MoO}_{2}\right.$ and $\left.\mathrm{MoO}_{3}\right)$, silicates 


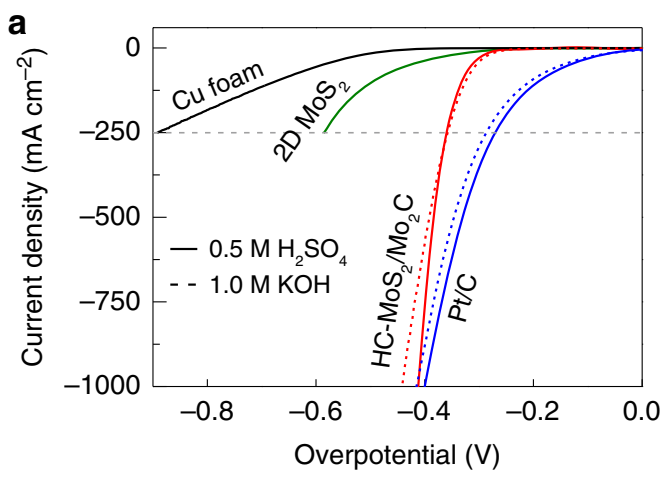

b

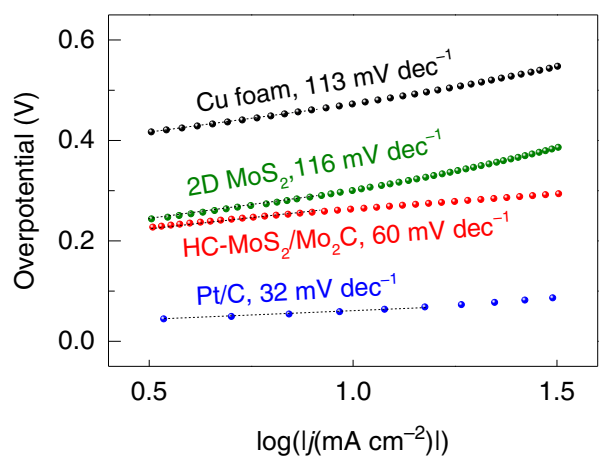

C

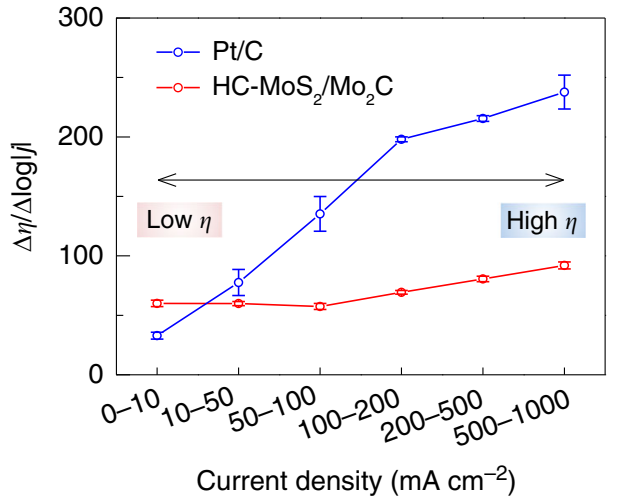

d

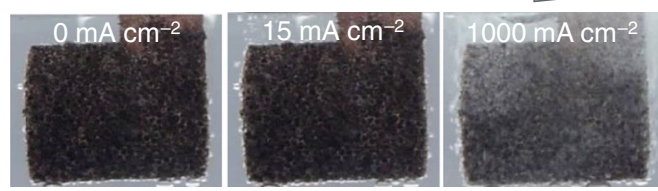

e
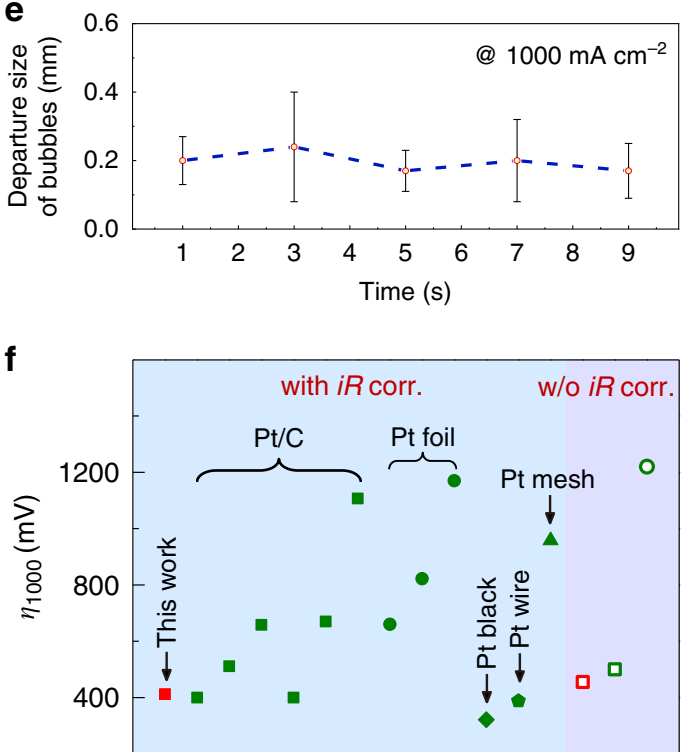

High-current-density HER catalysts

g

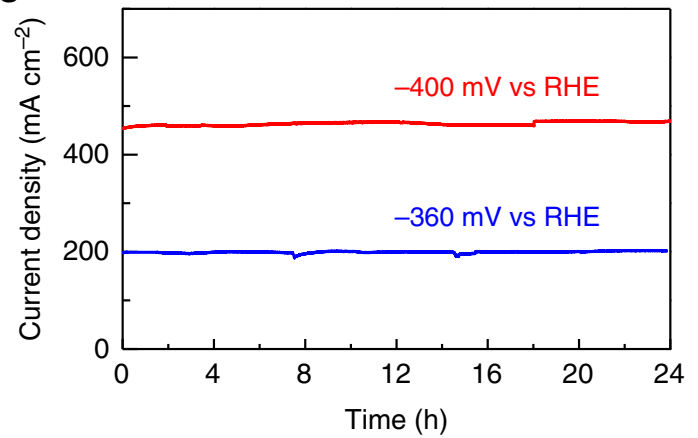

Fig. 3 Electrocatalytic performance of different catalysts for high-current-density HER. a Polarization curves, (b) Tafel plots, and (c) $\Delta \eta / \Delta \log |j|$ ratios of different catalysts in $0.5 \mathrm{M} \mathrm{H}_{2} \mathrm{SO}_{4}$ at a scan rate of $5 \mathrm{mV} \mathrm{s}^{-1}$ with $i R$ correction. d Photos and (e) corresponding size distribution of $\mathrm{H}_{2}$ bubbles leaving the surfaces of $\mathrm{HC}-\mathrm{MoS}_{2} / \mathrm{Mo}_{2} \mathrm{C}$ catalysts. $\mathbf{f}$ A comparison of the HER performance of $\mathrm{HC}-\mathrm{MoS}_{2} / \mathrm{Mo}_{2} \mathrm{C}$ catalysts and Pt-based catalysts we tested and previously reported (see details in Supplementary Table 2). The "w/o $i R$ corr." and "with $i R$ corr." in (f) mean without and with $i R$ correction. g Chronoamperometric response ( $i-t$ ) curves for hydrogen evolution reaction (HER) using $\mathrm{HC}-\mathrm{MoS}_{2} / \mathrm{Mo}_{2} \mathrm{C}$ at current densities of 200 and $\sim 500 \mathrm{~mA} \mathrm{~cm}-2$ for $24 \mathrm{~h}$, corresponding to potentials of -360 and $-400 \mathrm{mV}$ vs reversible hydrogen electrode (RHE) without $i R$ correction. The error bars show the standard derivation in (c) and (d).

and few other compositions (Supplementary Figs. 23-25). Note that its current price is only $10^{-2}, 10^{-4}, 10^{-5}$ times those of industrial-grade $\mathrm{MoS}_{2}$, high-purity $\mathrm{MoS}_{2}$, and Pt, respectively (Fig. 4b). It is therefore reasonable to use this raw bulk material to explore industrial catalyst production. A thousand liters of $2 \mathrm{D}$ $\mathrm{MoS}_{2}$ dispersions $\left(\sim 10 \mathrm{mg} \mathrm{mL}^{-1}\right)$ have now been produced in which the 2D MoS flakes have an average size of $50-100 \mathrm{~nm}$ (Supplementary Fig. 26). We have therefore shown that 2D MoS can be mass produced from a cheap molybdenite concentrate.

We then tested the HER performance of this $\mathrm{MoS}_{2}$ mineralbased catalyst. Similar to the earlier experiment, a large amount of 2D $\mathrm{MoS}_{2}\left(10 \mathrm{mg} \mathrm{mL}^{-1}\right)$ was loaded onto a conductive support followed by thermal treatment. Because this $2 \mathrm{D} \mathrm{MoS}$ was mass produced, the size of the working electrode can be made much bigger. We have therefore constructed working electrodes with areas of 1 and $5 \mathrm{~cm}^{2}$, both of which showed good uniformity (Supplementary Fig. 27). To the best of our knowledge, the use of such large-scale produced cheap $\mathrm{MoS}_{2}$ mineral as HER catalysts have not been reported previously. The difference in the HER performance between the $\mathrm{MoS}_{2}$ mineral-based and high-purity $\mathrm{MoS}_{2}$-based catalysts has been measured. The $\mathrm{MoS}_{2}$ mineralbased catalyst showed a good HER performance at high current densities. For example, it showed a $541 \mathrm{mV} @ 1000 \mathrm{~mA} \mathrm{~cm}^{-2}$, only $30 \%$ below the value for $\mathrm{HC}-\mathrm{MoS}_{2} / \mathrm{Mo}_{2} \mathrm{C}$ (Supplementary Fig. 28). The good HER performance of the bigger electrode was further demonstrated by EIS (Supplementary Fig. 29), which is quite encouraging because a large amount of HER-inert impurities, e.g., silicates, are present in $\mathrm{MoS}_{2}$ concentrates and 
a

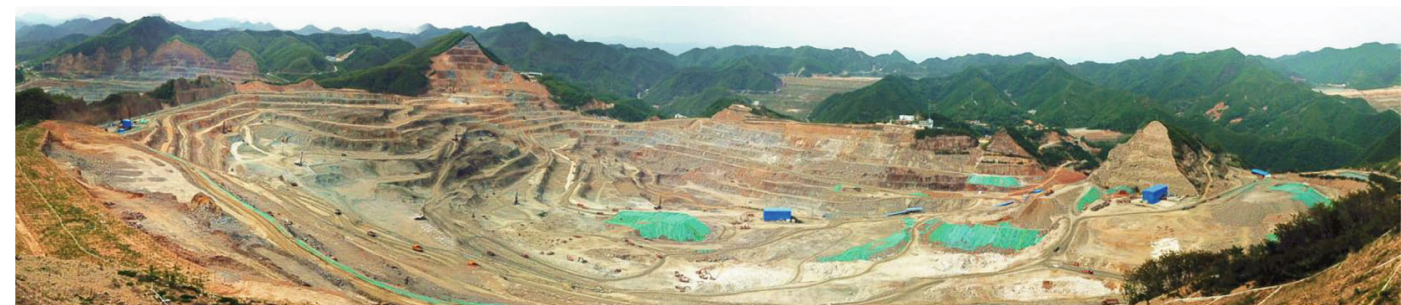

b
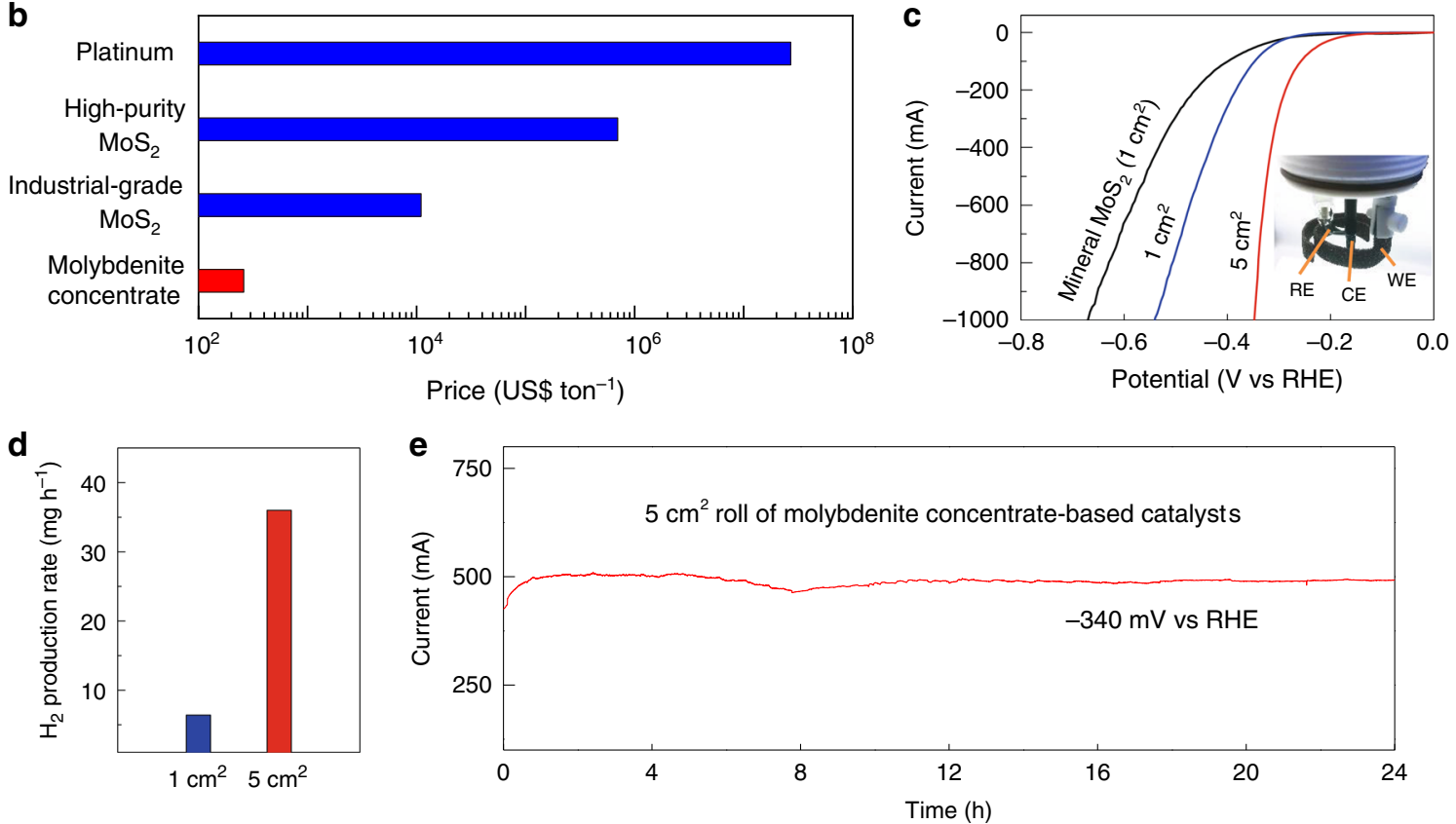

Fig. $4 \mathbf{M o S}_{\mathbf{2}}$ mineral catalysts from cheap molybdenite concentrates for high-current-density HER. a Bird's eye view of the Sandaozhuang open-pit molybdenite mine in Luoyang, China. Reproduced from Ref. ${ }^{28}$. The length of the field is around $1.5 \mathrm{~km}$. $\mathbf{b}$ Commodity price differences between platinum, high-purity $\mathrm{MoS}_{2}$, industrial-grade $\mathrm{MoS}_{2}$, and molybdenite concentrate. c Polarization curves of the different catalysts in $0.5 \mathrm{M} \mathrm{H}_{2} \mathrm{SO}_{4}$ at a scan rate of $5 \mathrm{mV} \mathrm{s}^{-1}$ with $i R$ correction. Inset is an optical image of a three-electrode electrolyzer for larger working electrodes. $\mathbf{d ~} \mathrm{H}_{2}$ production rate of different molybdenite concentrate-based catalysts to produce hydrogen under $-390 \mathrm{mV}$ vs RHE without $i R$ correction. e Chronoamperometric response ( $i-t$ ) curve of a $5 \mathrm{~cm}^{2}$ roll of cheap mineral-based catalyst for HER at current of $\sim 500 \mathrm{~mA}$ over $24 \mathrm{~h}$.

the catalytic performance can be further improved as discussed in Supplementary Figs. 11 and 12. The polarization curves of different working electrodes in a $\mathrm{H}_{2} \mathrm{SO}_{4}(0.5 \mathrm{M})$ solution are shown in Fig. $4 \mathrm{c}$ and S30. They show that the $5 \mathrm{~cm}^{2}$ working electrode achieves a current of $1000 \mathrm{~mA}$ at $347 \mathrm{mV}$, which is 194 $\mathrm{mV}$ less than for a $1 \mathrm{~cm}^{2}$ electrode. We also calculated the $\mathrm{H}_{2}$ production rate for different working electrodes (Fig. $4 \mathrm{~d}$ and Supplementary Table 4) and found that the performance of the 5 $\mathrm{cm}^{2}$ electrode $\left(38 \mathrm{mg} \mathrm{h}^{-1}\right)$ was an almost perfect scale-up from the $1 \mathrm{~cm}^{2}$ electrode $\left(7.4 \mathrm{mg} \mathrm{h}^{-1}\right)$, indicating the possibility of industrial use. Furthermore, the $\mathrm{MoS}_{2}$ mineral-based catalyst exhibited good durability, maintaining its performance at the current of $500 \mathrm{~mA}$ for more than $24 \mathrm{~h}$ (Fig. 4e).

The fabrication method for the $\mathrm{HC}-\mathrm{MoS}_{2} / \mathrm{Mo}_{2} \mathrm{C}$ catalyst has noticeable advantages over other methods such as solvothermal synthesis, gas-solid reaction, tip sonication, and Li intercalation (Fig. 5a and Supplementary Table 1). For example, the production rate of exfoliated $2 \mathrm{D} \mathrm{MoS}$ is $\sim 1.3 \mathrm{gh}^{-1}$, which is one to two orders of magnitude higher than those of other methods for synthesizing $\mathrm{MoS}_{2}$-based or even other TMDCbased catalysts using the most ideal assumptions. Our catalyst also works well at high current densities up to $1000 \mathrm{~mA} \mathrm{~cm}^{-2}$ giving it a big advantage in both production rate and working current density. The $2 \mathrm{D} \mathrm{MoS}_{2}$ ink also has the advantage of being able to be added to electrodes by spraying and dipping. The $\mathrm{MoS}_{2}$ mineral-based catalyst also has a low price of only $10 \mathrm{US} \$ \mathrm{~m}^{-2}$ excluding the cost of the support, almost 30 times lower than commercial Pt/C catalysts (Fig. 5b and Supplementary Table 5). Possible replacement of the $\mathrm{Mo}_{2} \mathrm{C}$ additive by cheaper materials would further reduce the overall cost. While the result presented here is a notable achievement, we note that a more comprehensive analysis will be the subject for future study. Taken together, these results indicate the huge potential of our high-throughput method for fabricating cheap, high-performance, and durable $\mathrm{MoS}_{2}$-based catalysts from minerals that are suitable for largescale $\mathrm{H}_{2}$ production.

\section{Discussion}

We have reported a high-throughput and scalable method for production of $\mathrm{MoS}_{2}$-based ink-type electrocatalysts, which combines scalable top-down exfoliation and simple thermal treatment. The catalysts exhibit decent performance for high-currentdensity HER, which is also verified by using mineral. Note that our catalyst with good high-current-density HER performance has been produced from cheap and earth abundant molybdenite mineral nature resources, giving it a huge potential for large-scale industry hydrogen production. Besides molybdenite minerals for 

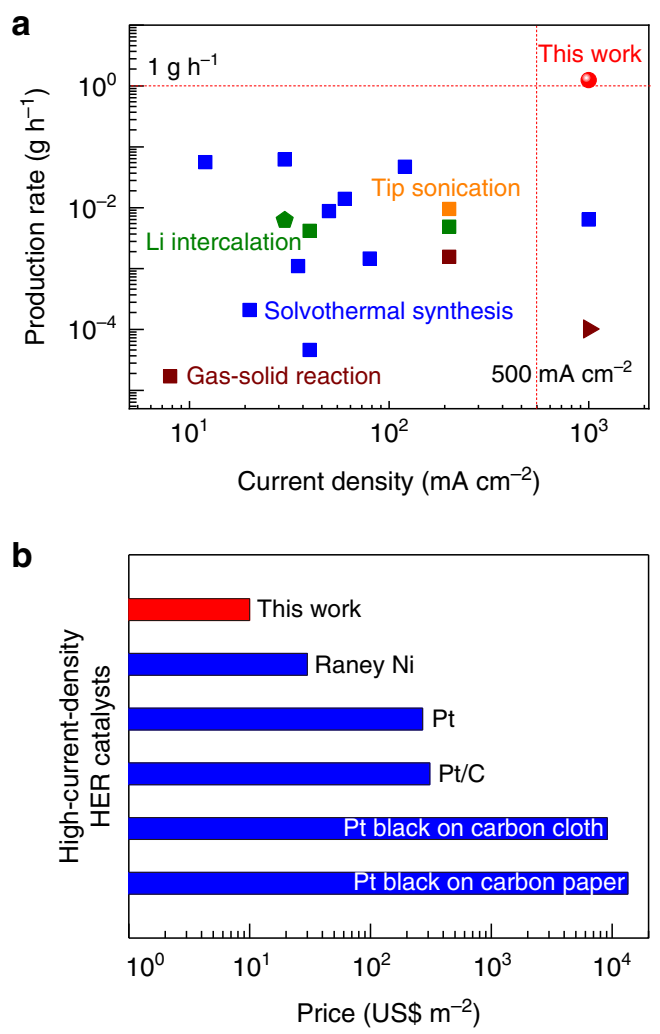

Fig. 5 High-efficiency and low-cost production of $\mathrm{MoS}_{2}$ mineral-based catalysts from cheap molybdenite concentrate for high-current-density HER. a A comparison of the fabrication rate and highest tested current density of transition metal dichalcogenide-based HER catalysts by different methods. Details for data points are shown in Supplementary Table 1. b A comparison of the catalyst cost compared to commercial electrocatalysts for HER, showing the ultralow cost of the $\mathrm{HC}-\mathrm{MoS}_{2} / \mathrm{Mo}_{2} \mathrm{C}$ catalyst. Note that the support costs of $\mathrm{HC}-\mathrm{MoS}_{2} / \mathrm{Mo}_{2} \mathrm{C}$, Raney Ni, Pt and Pt/C catalysts are excluded.

HER reported in this work, the method could be extended to the exfoliation of other layer materials from abundant natural resources for the mass production of electrocatalysts toward different electrochemical technologies.

\section{Methods}

Exfoliation of 2D $\mathbf{M o S}_{\mathbf{2}}$. All chemicals were used as received without further purification. The 2D MoS 2 was exfoliated by modifying a method previously reported ${ }^{28}$. The bulk $\mathrm{MoS}_{2}$ (10 g, with an average particle size of $\left.1-2 \mu \mathrm{m}\right)$ and the $\mathrm{Mo}_{2} \mathrm{C}(20 \mathrm{~g}$, with an average particle size of $44 \mu \mathrm{m})$ powders were mixed together and added into a rotational grinding apparatus (Retsch RM 200, Germany). As a result, the $\mathrm{MoS}_{2}$ was exfoliated into $2 \mathrm{D} \mathrm{MoS}_{2}$ after grinding for $9 \mathrm{~h}$ in an ambient atmosphere. For mineral exfoliation, molybdenite concentrate $(20 \mathrm{~g}$, from the Sandaozhuang open-pit mine, Luoyang, China) was used in place of the commercial $\mathrm{MoS}_{2}$ powder.

Thermal treatment of 2D MoS 2 to form $\mathrm{HC}-\mathrm{MoS}_{2} / \mathrm{Mo}_{2} \mathrm{C}$ electrocatalyst. First, the $2 \mathrm{D} \mathrm{MoS}_{2}$ was loaded onto a $\mathrm{Cu}$ foam that had been cleaned by diluted $\mathrm{HCl}$, water, and acetone. The exfoliated $2 \mathrm{D} \mathrm{MoS} 2(600 \mathrm{mg})$ was added to a mixture of ethanol $(18 \mathrm{~mL})$ and water $(2 \mathrm{~mL})$ and shaken for $10 \mathrm{~s}$ to produce a suspension was dropped onto the $\mathrm{Cu}$ foam $\left(1 \times 1 \mathrm{~cm}^{2}\right)$ with different mass loadings $(2-12 \mathrm{mg} 2 \mathrm{D}$ $\mathrm{MoS}_{2}$ ). Other conductive supports, Ti substrate and carbon cloth, were also examined. Second, the conductive supports loaded with $2 \mathrm{D} \mathrm{MoS}$ were thermal treated. In a typical procedure, $\mathrm{Cu}$ foam loaded with $2 \mathrm{D} \mathrm{MoS}_{2}$ was placed in a quartz boat in the center of a 1.5 in. diameter quartz tube furnace. For $\mathrm{H}_{2}$ treat ment, the furnace was first kept at given temperature $\left(650,750\right.$, or $\left.850^{\circ} \mathrm{C}\right)$ in a mixture of $\operatorname{Ar}(25 \mathrm{sccm})$ and $\mathrm{H}_{2}(7.5 \mathrm{sccm})$ for different times $(10,30,100$, or $180 \mathrm{~min}$ ), after which $\mathrm{S}$ vacancies had been formed in the $2 \mathrm{D} \mathrm{MoS}_{2}$. This was followed by $\mathrm{CH}_{4}$ treatment, in which the $\mathrm{H}_{2}$-treated sample was held at an optimum temperature of $750^{\circ} \mathrm{C}$ in a mixture of $\mathrm{Ar}(25 \mathrm{sccm}), \mathrm{H}_{2}(2.5 \mathrm{sccm})$ and $\mathrm{CH}_{4}$ $(2.5 \mathrm{sccm})$ for different times $(10,30,60$ or $180 \mathrm{~min})$ in order to partially convert the $\mathrm{MoS}_{2}$ into $\mathrm{Mo}_{2} \mathrm{C}$ nanocrystals. The final optimized sample is denoted $\mathrm{HC}$ $\mathrm{MoS}_{2} / \mathrm{Mo}_{2} \mathrm{C}$. The Pt/C electrocatalysts loaded on high-surface-area $\mathrm{Cu}$ foams were treated under the same optimized conditions.

Materials characterization. The surface morphology of the $\mathrm{HC}-\mathrm{MoS}_{2} / \mathrm{Mo}_{2} \mathrm{C}$ samples was characterized by SEM ( $5 \mathrm{kV}$, Hitachi SU8010, Japan). The thickness of the $2 \mathrm{D} \mathrm{MoS}_{2}$ flakes was measured by AFM (Bruker Dimension Icon, Germany). TEM and HRTEM were carried out by using an electron acceleration voltage of $300 \mathrm{kV}$ (FEI Tecnai F30, USA). Structural and chemical analyses of the samples were performed by powder XRD $(\mathrm{Cu} \mathrm{Ka}$ radiation, $\lambda=0.15418 \mathrm{~nm}$, Bruker D8 Advance, Germany), while Raman spectra were collected using $532 \mathrm{~nm}$ laser as the excitation light with a beam size of $\sim 1 \mu \mathrm{m}$ (Horiba LabRAB HR800, Japan).

Electrochemical measurements. A standard three-electrode electrolyzer with $\mathrm{H}_{2} \mathrm{SO}_{4}(0.5 \mathrm{M})$ or $\mathrm{KOH}(1.0 \mathrm{M})$ was used in all tests, with a saturated calomel electrode (SCE) and a graphite rod as the reference and counter electrodes, respectively. Pt counter electrode is used for taking videos. The scan rates were $5 \mathrm{mV} \mathrm{s}^{-1}$ for the linear sweep voltammetry tests and the scan rates for the cyclic voltammetry tests have been noted in the captions of the related figures. For fair comparison, a $85 \%$ iR correction was taken. Electrochemical active surface areas (ECSA) were obtained by measuring electrochemical double layer capacitance $\left(C_{\mathrm{dl}}\right)$ of catalysts. Faradaic efficiencies were defined as the ratio of $\mathrm{H}_{2}$ amount collected in experiment to the amount in theory, where $\mathrm{H}_{2}$ was collected by water drainage method. Stability tests were performed by chronoamperometry measurements method.

\section{Data availability}

Source data are provided with this paper.

Received: 1 February 2020; Accepted: 9 June 2020; Published online: 24 July 2020

\section{References}

1. Cai, X., Luo, Y., Liu, B. \& Cheng, H.-M. Preparation of 2D material dispersions and their applications. Chem. Soc. Rev. 47, 6224-6266 (2018).

2. Kibsgaard, J. \& Chorkendorff, I. Considerations for the scaling-up of water splitting catalysts. Nat. Energy 4, 430-433 (2019).

3. Wang, X., Xu, C., Jaroniec, M., Zheng, Y. \& Qiao, S.-Z. Anomalous hydrogen evolution behavior in high-pH environment induced by locally generated hydronium ions. Nat. Commun. 10, 4876 (2019).

4. Zhang, B. et al. Interface engineering: The $\mathrm{Ni}(\mathrm{OH})_{2} / \mathrm{MoS}_{2}$ heterostructure for highly efficient alkaline hydrogen evolution. Nano Energy 37, 74-80 (2017).

5. National Minerals Information Center. Available from: https://www.usgs.gov/ centers/nmic/commodity-statistics-and-information.

6. King, L. A. et al. A non-precious metal hydrogen catalyst in a commercial polymer electrolyte membrane electrolyser. Nat. Nanotechnol. 14, 1071-1074 (2019).

7. Liu, D. et al. Atomically dispersed platinum supported on curved carbon supports for efficient electrocatalytic hydrogen evolution. Nat. Energy 4, 512-518 (2019).

8. Tiwari, J. N. et al. Multicomponent electrocatalyst with ultralow Pt loading and high hydrogen evolution activity. Nat. Energy 3, 773-782 (2018).

9. Li, M. et al. Single-atom tailoring of platinum nanocatalysts for highperformance multifunctional electrocatalysis. Nat. Catal. 2, 495-503 (2019).

10. Meng, C. et al. Atomically and electronically coupled Pt and CoO hybrid nanocatalysts for enhanced electrocatalytic performance. Adv. Mater. 29, 1604607 (2017).

11. Meyer, $\mathrm{S}$. et al. Transition metal carbides (WC, $\mathrm{Mo}_{2} \mathrm{C}, \mathrm{TaC}, \mathrm{NbC}$ ) as potential electrocatalysts for the hydrogen evolution reaction (HER) at medium temperatures. Int. J. Hydrogen Energy 40, 2905-2911 (2015).

12. Han, N. et al. Nitrogen-doped tungsten carbide nanoarray as an efficient bifunctional electrocatalyst for water splitting in acid. Nat. Commun. 9, 924 (2018).

13. Luo, Y. et al. Morphology and surface chemistry engineering toward $\mathrm{pH}-$ universal catalysts for hydrogen evolution at high current density. Nat. Commun. 10, 269 (2019).

14. Voiry, D. et al. Conducting $\mathrm{MoS}_{2}$ nanosheets as catalysts for hydrogen evolution reaction. Nano Lett. 13, 6222-6227 (2013).

15. Jaramillo, T. F. et al. Identification of active edge sites for electrochemical $\mathrm{H}_{2}$ evolution from $\mathrm{MoS}_{2}$ nanocatalysts. Science 6, 100-102 (2007).

16. Luo, Y. et al. Two-dimensional $\mathrm{MoS}_{2}$ confined $\mathrm{Co}(\mathrm{OH})_{2}$ electrocatalysts for hydrogen evolution in alkaline electrolytes. ACS Nano 12, 4565-4573 (2018).

17. Shi, J. et al. Two-dimensional metallic tantalum disulfide as a hydrogen evolution catalyst. Nat. Commun. 8, 958 (2017). 
18. Voiry, D. et al. Enhanced catalytic activity in strained chemically exfoliated $\mathrm{WS}_{2}$ nanosheets for hydrogen evolution. Nat. Mater. 12, 850-855 (2013).

19. Yu, Y. et al. High phase-purity $1 \mathrm{~T}^{\prime}-\mathrm{MoS}_{2}$ and $1 \mathrm{~T}^{\prime}-\mathrm{MoSe}_{2}$-layered crystals. Nat. Chem. 10, 638-643 (2018).

20. Luo, Y. et al. Unsaturated single atoms on monolayer transition metal dichalcogenides for ultrafast hydrogen evolution. ACS Nano 14, 767-776 (2020).

21. Menezes, P. W. et al. Helical cobalt borophosphates to master durable overall water-splitting. Energy Environ. Sci. 12, 988-999 (2019).

22. Yang, J. et al. Ultrahigh-current-density niobium disulfide catalysts for hydrogen evolution. Nat. Mater. 18, 1309-1314 (2019).

23. Berit Hinnemann et al. Biomimetic hydrogen evolution: $\mathrm{MoS}_{2}$ nanoparticles as catalyst for hydrogen evolution. J. Am. Chem. Soc. 127, 5308-5309 (2005).

24. Gopalakrishnan, D., Damien, D. \& Shaijumon, M. M. $\mathrm{MoS}_{2}$ Quantum Dotinterspersed exfoliated $\mathrm{MoS}_{2}$ nanosheets. ACS Nano 8, 5297-5303 (2014).

25. Lukowski, M. A. et al. Enhanced hydrogen evolution catalysis from chemically exfoliated metallic $\mathrm{MoS}_{2}$ nanosheets. J. Am. Chem. Soc. 135, 10274-10277 (2013).

26. Chen, Y. C. et al. Structurally deformed $\mathrm{MoS}_{2}$ for electrochemically stable, thermally resistant, and highly efficient hydrogen evolution reaction. $A d v$. Mater. 29, 1703863 (2017).

27. Yoon, J. et al. Highly flexible and transparent multilayer $\mathrm{MoS}_{2}$ transistors with graphene electrodes. Small 9, 3295-3300 (2013).

28. Zhang, C. et al. Mass production of two-dimensional materials by intermediate-assisted grinding exfoliation. Natl Sci. Rev. 7, 324-332 (2020).

29. Zhong, Y. et al. Transition metal carbides and nitrides in energy storage and conversion. Adv. Sci. 3, 1500286 (2016).

30. Jeon, J. et al. Epitaxial synthesis of molybdenum carbide and formation of a $\mathrm{Mo}_{2} \mathrm{C} / \mathrm{MoS}_{2}$ hybrid structure via chemical conversion of molybdenum disulfide. ACS Nano 12, 338-346 (2018).

31. Xiao, T.-C. et al. Preparation and characterisation of bimetallic cobalt and molybdenum carbides. J. Catal. 202, 100-109 (2001).

32. $\mathrm{Hu}, \mathrm{J}$. et al. Nanohybridization of $\mathrm{MoS}_{2}$ with layered double hydroxides efficiently synergizes the hydrogen evolution in alkaline media. Joule $\mathbf{1}$, 383-393 (2017).

\section{Acknowledgements}

The authors acknowledge support from the National Natural Science Foundation of China (Nos. 51722206 and 51920105002), the Youth 1000-Talent Program of China, Guangdong Innovative and Entrepreneurial Research Team Program (No. 2017ZT07C341), the Bureau of Industry and Information Technology of Shenzhen for the "2017 Graphene Manufacturing Innovation Center Project" (No. 201901171523), and the Development and Reform Commission of Shenzhen Municipality for the development of the "Low-Dimensional Materials and Devices" discipline.

\section{Author contributions}

C.Z., Y.L., H.C., and B.L. conceived the idea. C.Z. synthesized materials and performed XRD, Raman, SEM, and AFM characterization and electrochemical tests. L.Y. helped in materials exfoliation. J.T. performed TEM characterization and analysis. Q.Y. helped in electrochemical tests. Y.L., F.Y., and Z.Z. took part in the electrochemical measurements and discussion. B.L. supervised the project and directed the research. C.Z., Y.L., H.C., and B.L. interpreted the results. C.Z., Y.L., and B.L. wrote the manuscript with feedbacks from the other authors.

\section{Competing interests}

Patents related to this research have been filed by Tsinghua-Berkeley Shenzhen Institute, Tsinghua University. The University's policy is to share financial rewards from the exploitation of patents with the inventors.

\section{Additional information}

Supplementary information is available for this paper at https://doi.org/10.1038/s41467020-17121-8.

Correspondence and requests for materials should be addressed to B.L.

Peer review information Nature Communication thanks the anonymous reviewers for their contributions to the peer review of this work. Peer review reports are available

Reprints and permission information is available at http://www.nature.com/reprints

Publisher's note Springer Nature remains neutral with regard to jurisdictional claims in published maps and institutional affiliations.

Open Access This article is licensed under a Creative Commons Attribution 4.0 International License, which permits use, sharing, adaptation, distribution and reproduction in any medium or format, as long as you give appropriate credit to the original author(s) and the source, provide a link to the Creative Commons license, and indicate if changes were made. The images or other third party material in this article are included in the article's Creative Commons license, unless indicated otherwise in a credit line to the material. If material is not included in the article's Creative Commons license and your intended use is not permitted by statutory regulation or exceeds the permitted use, you will need to obtain permission directly from the copyright holder. To view a copy of this license, visit http://creativecommons.org/ licenses/by/4.0/.

(C) The Author(s) 2020 